\title{
INVESTIGATION OF HRPF2 GENE DELETION IN PLASMODIUM FALCIPARUM IN NORTHWESTERN NIGERIA
}

\author{
Dayyabu SHEHU ${ }^{1 *}$, Farida Muhammad AMINU², Shehu DANLAMI ${ }^{3}$, Jamila Ahmed MASHI ${ }^{1}$
}

${ }^{* 1}$ Department of Biochemistry, College of Health Sciences, Bayero University, Kano, PMB 3011, Kano Nigeria

${ }^{2}$ Sokoto State Ministry of Health, Nigeria

${ }^{3}$ Department of Nursing, College of Medicine, Kaduna State University, Kaduna, Nigeria

*Correspondence:

Dayyabu SHEHU

dshehu.bch@buk.edu.ng

Received: 05 May 2021; Accepted: 24 May 2021; Published: 30 June 2021

\begin{abstract}
Malaria Rapid Diagnostic Tests (RDTs) plays an important role in malaria management and control. The Pf HRP2 based RDT kit is the most widely used RDT for malaria diagnosis in Nigeria but is affected by the deletion of HRP2 gene in Plasmodium falciparum parasites. Therefore, identifying the prevalence and distribution of Plasmodium falciparum parasites with deleted Pf HRP2 is important for malaria control. Pf HRP2 gene deletion was assessed in this study by first carrying out Giemsa stained thick blood film microscopy and Pf HRP2 RDT strip test. The samples were further analyzed for molecular examination by PCR assay for multiple single-copy genes (Pf Cox3, Pf HRP2, Pf HRP3 and Pf Beta tubulin). This study found the existence of eight (8) Plasmodium falciparum isolates lacking the HRP2 gene in the samples analyzed, this necessitates the need to develop a unique RDT Kit targeting other housekeeping genes unique for Plasmodium falciparum with far greater sensitivity than the current ones as to reduce the chances of false negative RDT result as well as developing unique RDT Kits targeting both PfHRP2 and PfHRP3 genes concomitantly in order to reduce the chances of having a false positive RDT results.
\end{abstract}

Keywords: Malaria, Plasmodium falciparum, Gene deletion, RDT.

\section{Introduction}

Malaria is one of the major causes of mortality and morbidity in the tropics and subtropics particularly in Africa (Skeet, 2005). Early diagnosis is very important for disease management and effective treatment of malaria. Diagnosis of malaria using microscopic examination of thin and thick blood smears is still the gold standard (Siahaan, 2018). However, The World Health Organization recently recommended the adoption of malaria rapid diagnostic tests (RDTs) as a universal testing to confirm the presence of malaria parasites in regions where microscopic examination cannot be performed (Gillet et al., 2011).

Malaria RDTs are immunochromatographic tests that detect proteins released from parasitized red blood cells. It has been designed to detect either Plasmodium falciparum specifically, or $P$. falciparum in addition to another human malaria parasite or detect all human malaria parasites 
(Cunningham et al., 2019). Malaria RDT kits mainly detects antigens $P$. falciparum Histidine Rich Protein 2, parasite Lactate Dehydrogenase (pLDH), and parasite Aldolase (pALD), although pALD and pLDH appear to be highly conserved (Lee et al., 2006; Maltha et al., 2010). The specific antigen remains in the circulation for up to 4 weeks after the malaria parasites clearance due to its high abundance and heat stability (Iqbal et al., 2004).

A structural homologue of PfHRP-2, PfHRP-3, has been found to have cross reactivity with some monoclonal antibodies directed against PfHRP-2 (Lee et al., 2012). Thus, although PfHRP-2 based RDT kits have the highest sensitivities, they also have high false positive rates (Baiden et al., 2012). Therefore, accurate diagnosis of malaria by PfHRP-2 RDT kits can be affected by the pfhrp2 and or pfhrp3 genotype of the parasite, the concentration of PfHRP-2 antigen produced by the parasite and also the prolonged existence of PfHRP-2 antigen after parasite clear (Wurtz et al., 2013).

Diagnosis of malaria by RDT without additional confirmation of parasitaemia nowadays become a major problem due to false positive test results, which leads to the unnecessary administration of anti-malarial drugs when no malaria parasites are actually present in the patient (Gerstl et al., 2010). False positive RDT test results are frequently obtained immediately following an antimalarial drug regimen, when parasites are cleared or densities very low, but the antigen remains in circulation weeks later (Adu-Gyasi et al., 2012; Gerstl et al., 2010). Additionally, there is failure to produce the HRP2 target molecule for HRP2-based RDTs by the Plasmodium falciparum parasites without the "central repeat region of the HRP2 gene" which may cause false-negative RDTs (Dorado et al., 2016; Gamboa et al., 2010; Koita et al., 2012). This could be due to gene deletion, frame shift mutation or alteration in protein, which may have also contributed to the variable performance of RDT test (Dorado et al., 2016).

Nowadays, concerns have been raised about the diagnostic threat and malaria control posed by parasites without hrp2 such as the effectiveness of PfHRP2-based RDTs in affected regions (Fontecha et al., 2018; Maltha et al., 2012). In response, the World Health Organization has prioritized efforts to address parasites with deletions of the pfhrp2 and/or pfhrp3 genes, for this reason, there is a little amount of data on the frequency of those parasites and the factors responsible for their selection. Recently, deletion of these genes was reported in population-based studies from Peru, Mali, Asia-Pacific region, India, Madagascar, in a clinical case in Uganda and as case report from Brazil (Baker et al., 2005; Maltha et al., 2012; Parr et al., 2017). However, such data is not available in Nigeria. This research sought to analyze the possibility of Pfhrp2 gene deletion in clinical isolates from northwestern Nigeria.

\section{Materials and methods}

\subsection{Materials}

\subsubsection{Study Area}

The study was conducted at Muhammadu Abdullahi Wase Specialist Hospital and Murtala Muhammad General Hospital situated within Kano metropolis, North West geopolitical zone of Nigeria. The area is located in Kano city and has a coordination of latitude $11.96^{\circ} \mathrm{N}$ and longitude $8.55^{\circ} \mathrm{E}$.

\subsubsection{Ethical Approval and Consent}

The ethical approval was obtained from the Research and Ethical Committees of the Kano State Ministry of Health (MOH/Off/797/T.I/872). Informed verbal consent was obtained from patients or their 
parents prior to blood collection with standard questionnaire.

\subsubsection{Study population}

Patients irrespective of age or sex, with clinical presentation of malaria through consultation and are referred for diagnostic evaluation of $P$. falciparum in vitro.

\subsubsection{Inclusion and Exclusion Criteria for Sample}

All samples with both positive malaria smear and RDT were excluded, as well as all samples with both negative malaria smear and RDT were also excluded. Whereas all samples with either a positive malaria smear and a negative RDT or samples with negative malaria smear and positive RDT were included.

\subsection{Methods}

\subsubsection{Determination of sample size}

The sample size was determined from standard formula for calculation of minimum sample size. Sample size ' $n$ ' was given by the formula, where $\mathrm{n}=138.29$ as a minimum number of samples for the study with $2 \%$ (3) of these subjects were added to the research for attrition, making a total of approximately 141 subjects ( Draugalis \& Plaza, 2009).

\subsubsection{Sample Collection}

Blood samples were collected via venopuncture into Ethylene diamine tetra acetic acid (EDTA) containers and were taken to the laboratory for examination.

\subsubsection{Microscopy}

Thick blood smears were made, then stained using 3\% Giemsa stain and examined 100 fields by oil immersion magnification in which the parasite density was estimated as described by (Wongsrichanalai et al., 2007).

\subsubsection{Rapid Diagnostic Test (RDT)}

The HRP2-based RDT (CareStart ${ }^{\mathrm{TM}}$ Malaria HRP2 Pf) was performed according to the manufacturer's instructions.

\subsubsection{DNA Extraction}

The EDTA anti-coagulated blood sample that was stored at $-4^{\circ} \mathrm{C}$ was allowed to thaw and vortexed, and then the DNA was extracted using D1800 Blood Genomic DNA Extraction kit (solarbio life science), according to the manufacturers protocol.

\subsubsection{Polymerase Chain Reaction (PCR) Amplification}

All the PCR reactions were performed by preparing a $20 \mathrm{ul}$ reaction mix containing $3 \mathrm{ul}$ of DNA template, $0.5 \mathrm{ul}$ of each forward and reverse primer, 10ul of high fidelity polymerase (Thermo fisher Scientific) and 6ul of nuclease free water. PCR reaction was set using 3-step PCR set up: 1) One (1) cycle of initial denaturation at $95^{\circ} \mathrm{C}$ for 3 minutes. 2) Thirty five cycles (35) cycles of denaturation at $94^{\circ} \mathrm{C}$ for 30 seconds and extension at $72^{\circ} \mathrm{C}$ for 30 seconds. However, other parameter for the annealing temperature varies depending on the primer used. (3) One (1) cycle of final extension at $72^{\circ} \mathrm{C}$ for 5 minutes.

PCR was performed using the following set of primers:

- PF COX3 GENE: Forward: (5' AGCGGTTAACCTTTCTTTTTCCTTAC G 3') and Reverse (5' AGTGCATCATGTATGACAGCATGTTT ACA 3').

- Annealing temperature used was $58^{\circ} \mathrm{C}$ for 30 seconds.

- PF HRP2 GENE: Forward: ATTCCGCATTTAATAATAACTTGTGT AGC and Reverse:

ATGGCGTAGGCAATGTGTGG.

- Annealing temperature used was $58.5^{\circ} \mathrm{C}$ for 30 seconds.

- PF HRP3 GENE: 5' TATCCGCTGCCGTTTTTGCTTCC 3' and Reverse: 5' TGCATGATGGGCATC ACCTG 3'.

- Annealing temperature used was $58^{\circ} \mathrm{C}$ for 30 seconds. 
- PF BETA TUBULIN GENE: Forward:

(5' AATAAATCATAATGATGT

GCGCAAGTGATCC 3') and Reverse: (5'

AATAAATCATAATCCTTTGTGGACAT TCTTCCTC 3').

- Annealing temperature used was $58^{\circ} \mathrm{C}$ for 30 seconds.

Agarose gel electrophoresis was performed on the PCR products. The electrophoresis was performed at $80 \mathrm{~V}$ for 1 hour 30 minutes using $5 \mu$ of gel ready DNA marker pipetted into the adjacent well. The PCR products were visualized using Alpha Imager Mini after staining with ethidium bromide.

\section{Results and discussion}

\subsection{Results}

Seventy (70) samples from patients attending Murtala Muhammad Specialist Hospital (MMSH) were analyzed for microscopy and RDT. Fifty five (55) samples appeared to be positive and fifteen (15) samples were negative for microscopy, while forty six (46) samples appeared to be positive and twenty four (24) samples were negative for RDT (Table 1). Seventy (70) samples were also collected from Abdullahi Wase specialist Hospital (AWSH) and analyzed for microscopy and RDT. Forty seven (47) samples appeared to be positive and twenty three (23) samples were negative for microscopy, while twenty three (23) samples appeared to be positive and forty seven (47) samples were negative for RDT (Table 1).

Based on the method of Parr et al. (2018), only those samples that appeared RDTPositive/Microscopy negative and RDTnegative/Microscopy positive are eligible for further screening of Hrp2 gene deletion. Therefore the samples were subjected to a combination of rapid diagnostic and microscopy. Thirty eight (38) samples from MMSH were found to be both positive for microscopy and RDT while seven (7) samples were found to be both RDT and microscopy negative. Nine (9) samples were RDT positive/microscopy negative, while 16 sample were RDT negative/ microscopy positive (Table 1). Twenty two (22) samples from AWSH were found to be both microscopy and RDT positive, twenty three (23) sample were both microscopy and RDT negative, one (1) sample was RDT positive/microscopy negative, while twenty four (24) samples were RDT negative/microscopy positive (Table 2 ).

A total of fifty (50) samples from both hospitals were found to be microcopy positive/RDT negative and microscopy negative/RDT positive and were further analyzed for molecular examination in order to assess the possibility of PfHRP2 gene deletion in those samples. However, molecular genotyping was first performed for species identification of the malarial parasite. The samples were analyzed for Pf Cox 3 gene (Plasmodium falciparum genotyping) out of which only sixteen (16) samples appeared positive with the expected band size (508bp), while thirty four (34) samples were negative, possibly due to different specie of the malaria parasite (Fig. 1, 2, 3). Having confirmed the species of the malarial parasite, the sixteen (16) Cox3-gene positive samples were further analyzed for Pf HRP2 gene out of which five (5) samples appeared to be positive with expected band size (800bp, 900bp) and eleven (11) samples were negative possibly due to absence of the gene (Fig. 4). The eleven (11) Pf HRP2 gene negative samples were further amplified for Pf HRP3 gene were ten (10) samples were positive with expected band size (300bp, 400bp, 800bp) and one (1) sample was negative (Fig. 5). More so, Pf Beta tubulin final confirmation was performed on the one (1) Pf HRP3 gene negative sample which appeared to be negative either due to no or low limit of detection (Fig. 6). 
Table 1. Microscopy And RDT Results of Samples Analyzed from Murtala Muhammad Specialist Hospital and Abdullahi Wase specialist Hospital

\begin{tabular}{|l|l|l|l|l|l|l|}
\hline Hospital Name & \multicolumn{3}{|l|}{ Microscopy } & \multicolumn{3}{l|}{ Hrp2 RDT } \\
\hline MMSH & $\begin{array}{l}\text { Microscopy } \\
\text { positive }\end{array}$ & $\begin{array}{l}\text { Microscopy } \\
\text { negative }\end{array}$ & Total & $\begin{array}{l}\text { RDT } \\
\text { positive }\end{array}$ & $\begin{array}{l}\text { RDT } \\
\text { negative }\end{array}$ & Total \\
\cline { 2 - 8 } & 55 & 15 & 70 & 46 & 24 & 70 \\
\hline AWSH & 47 & 23 & 70 & 23 & 47 & 70 \\
\hline Total sample size & & & 140 & & & 140 \\
\hline
\end{tabular}

Table 2. Combination of Microscopy And RDT Results Of Samples Analyzed from Murtala Muhammad Specialist Hospital and Abdullahi Wase Specialist Hospital

\begin{tabular}{|l|l|l|l|l|l|}
\hline $\begin{array}{c}\text { Hospital } \\
\text { Name }\end{array}$ & $\begin{array}{c}\text { Hrp2 RDT } \\
\text { /microscopy } \\
\text { positive } \\
\mathbf{n}=\end{array}$ & $\begin{array}{c}\text { Hrp2 RDT } \\
\text { /microscopy } \\
\text { negative } \\
\mathbf{n}=\end{array}$ & $\begin{array}{c}\text { Hrp RDT } \\
\text { positive/microscopy } \\
\text { negative } \\
\text { n=(molecular } \\
\text { investigation) }\end{array}$ & $\begin{array}{c}\text { Hrp RDT } \\
\text { negative/microscopy } \\
\text { positive } \\
\text { n=(molecular } \\
\text { investigation) }\end{array}$ & Total \\
\hline MMSH & 38 & 7 & 9 & 16 & 70 \\
\hline AWSH & 22 & 23 & 10 & 24 & 70 \\
\hline $\begin{array}{l}\text { Total } \\
\text { sample } \\
\text { size =n }\end{array}$ & 60 & 30 & & 40 & 140 \\
\hline
\end{tabular}

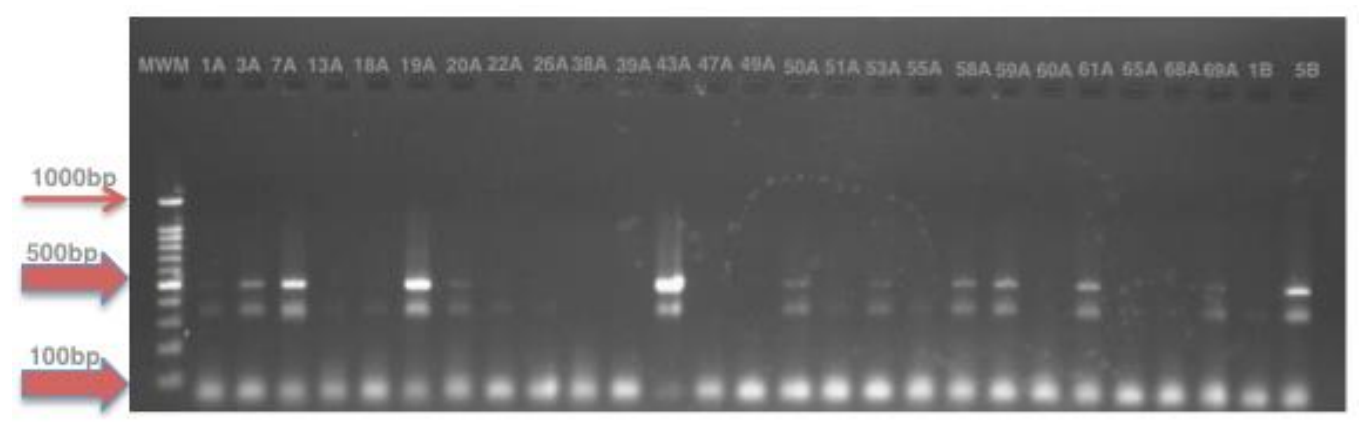

Fig. 1. Pf cox3 gene PCR (P. falciparum genotyping) amplification

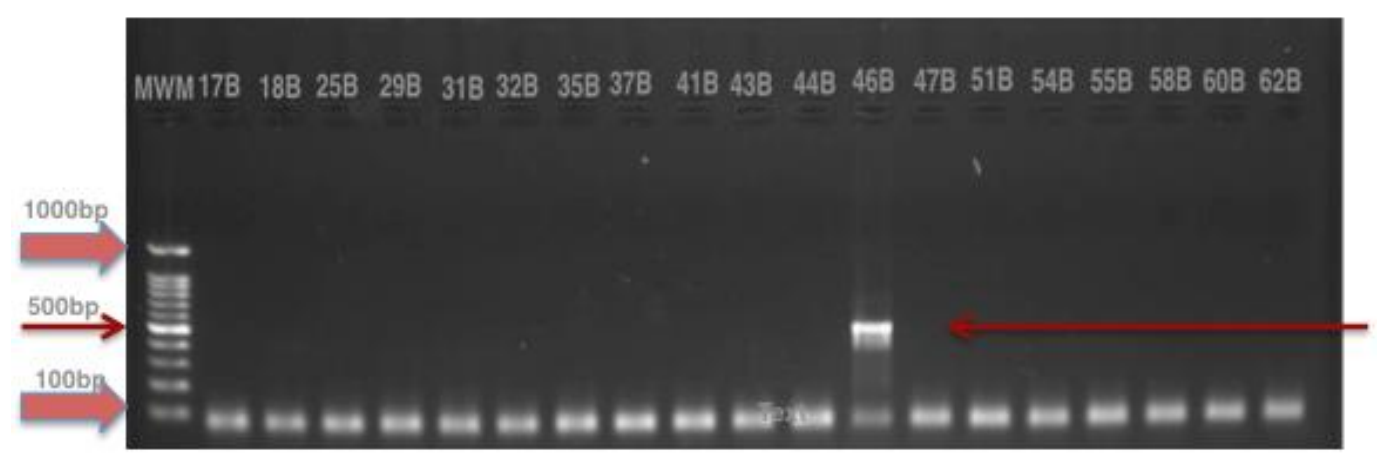

Fig. 2. Pf cox3 gene PCR (P. falciparum genotyping) amplification 


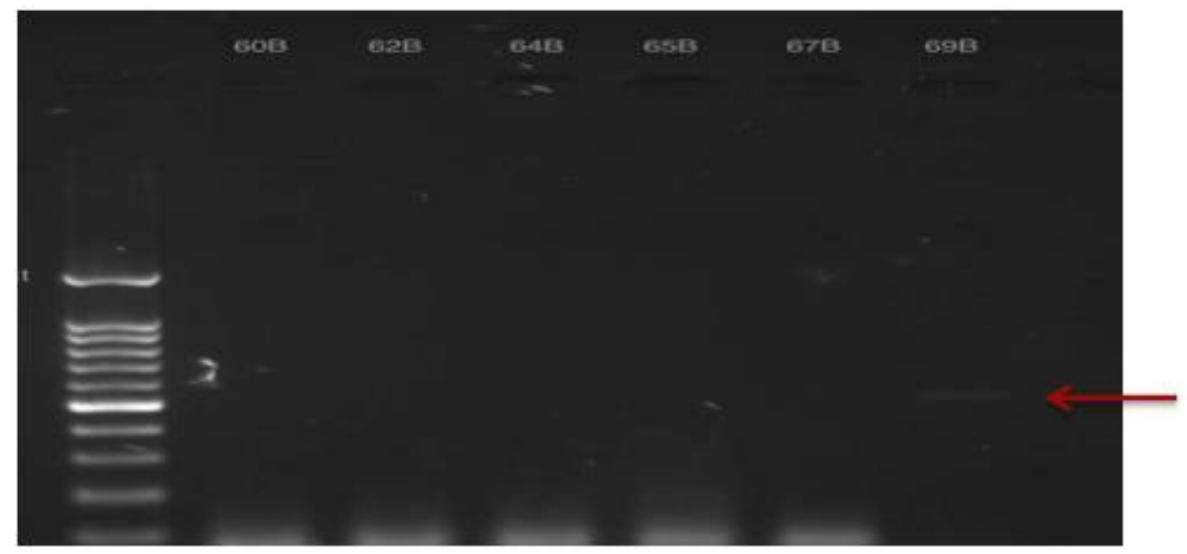

Fig. 3. Fig. 1, 2, 3. Pf cox3 gene PCR ( $P$. falciparum genotyping) amplification. MWM is the molecular weight marker while the arrows indicated the 508bp of the 16 successfully amplified Pf cox3 genes

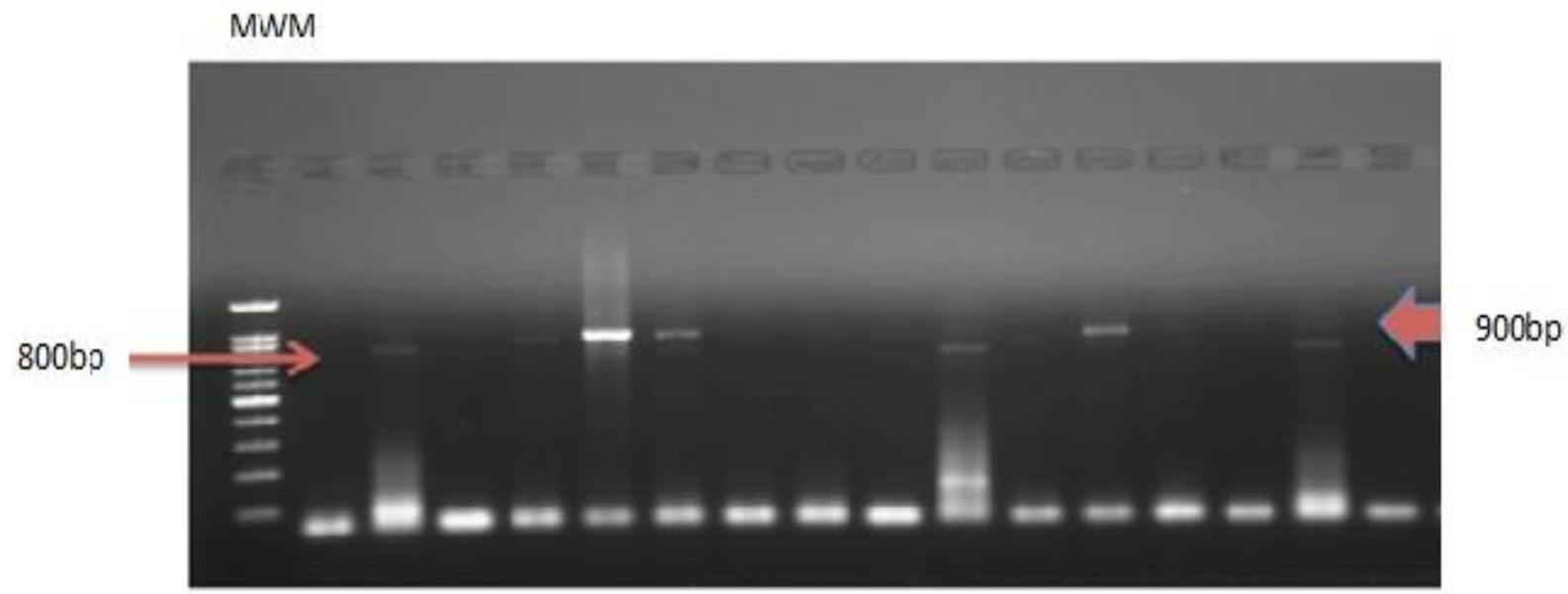

Fig. 4. Pf HRP2 gene amplification. Five (5) samples out of 16 were positive for Pf HRP2 gene with the expected band sizes of 800bp and 900bp

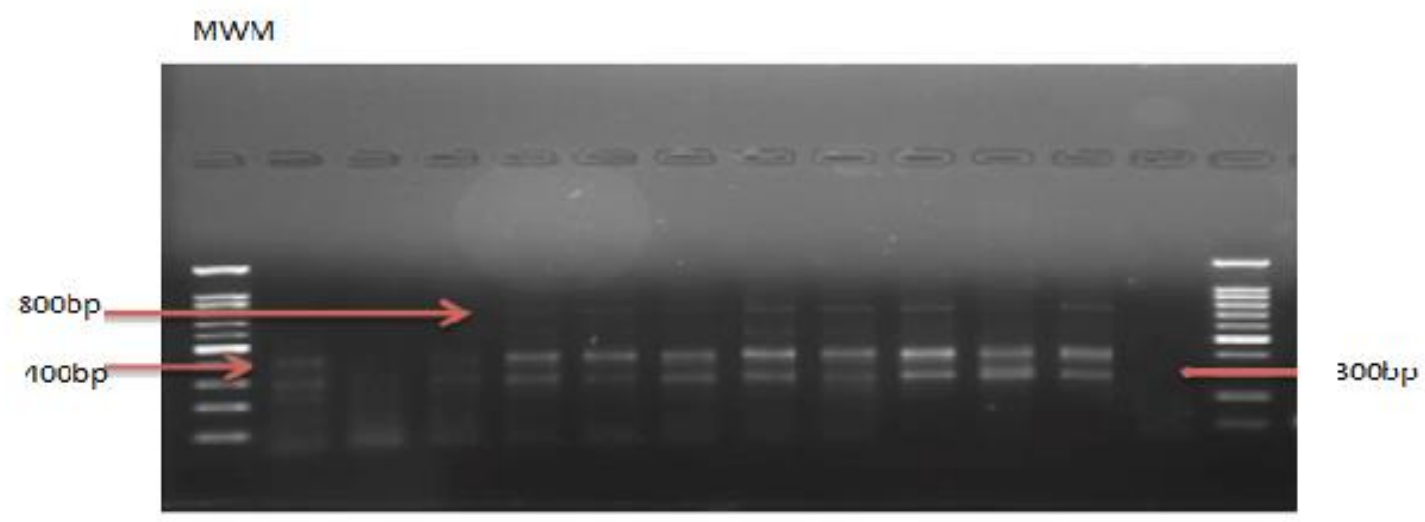

Fig. 5. Pf HRP3 gene amplification. Ten (10) samples out of 11 were positive for Pf HRP3 gene with the expected band sizes of 300bp, 400bp and 900bp 


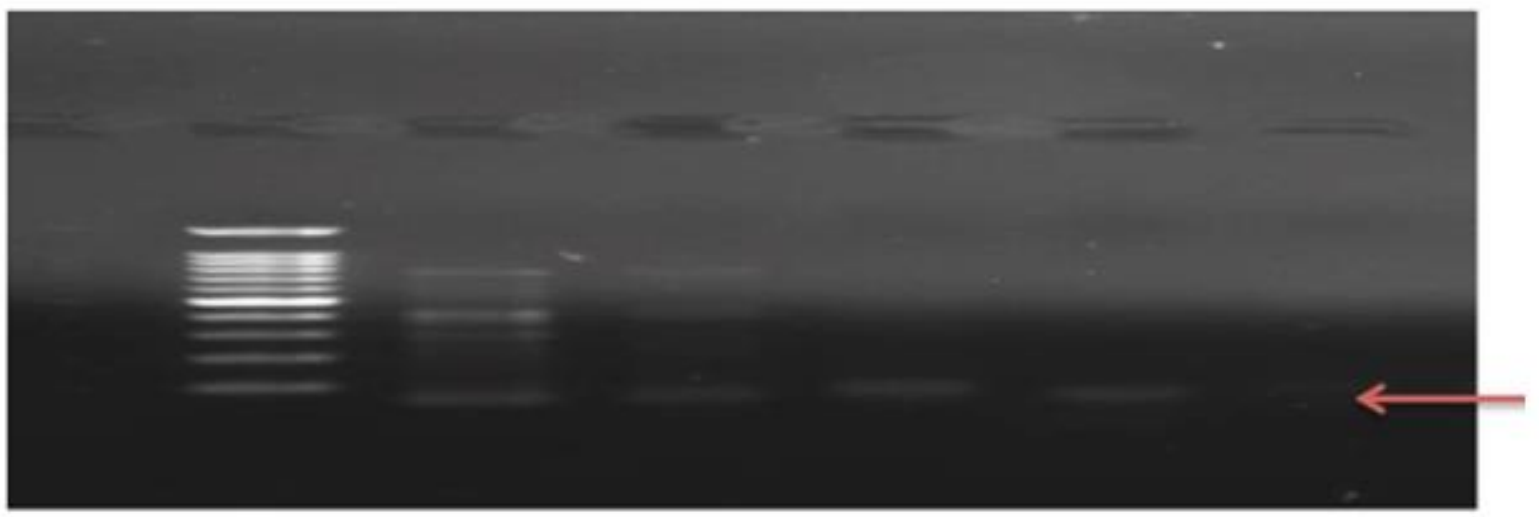

Fig. 6. Pf Beta tubulin gene amplification. No amplification was observed

\subsection{Discussion}

In sub-Saharan Africa, Pf HRP2 RDTs are the tests most commonly used and best recommended for parasitological confirmation of malaria in regions where microscopic examination cannot be performed before treatment. However, several reports have noted significant declines in the sensitivity of $\mathrm{Pf}$ HRP2 RDTs after declines in the intensity of transmission ( Kumar et al., 2013; Shakely et al., 2013). Thus, in this study Pf HRP2 RDT performance was examined in relation to microscopy, which is considered the gold standard (Zimmerman and Howes, 2015).

By employing the improved approach of testing algorithm for PCR-based detection of PfHRP2/3-negative $P$. falciparum, the identification of PfHRP2-negative parasites must be coupled with verification of $P$. falciparum parasitaemia and confirmation that parasite DNA is present (Kumar et al., 2019; Parr et al., 2017) . The presence of amplifiable DNA in PfHRP2-deleted samples were confirmed by PCR assay for multiple single copy genes (Pf Cox3, Pf HRP3 and Pf Beta tubulin). In the first stage, i.e. genotyping of $P$. falciparum, PCR amplification of Pf Cox3 gene showed 16 samples that appeared to be positive with an expected band size of about 508bp out of the 50 samples analyzed. The negative samples may likely not be from $P$. falciparum strain as Cox3-gene is solely used for genotyping Plasmodium falciparum (Echeverry et al., 2016).

Having confirmed the specie of the malarial parasite, the second stage is to confirm if there is Pf HRP2 gene deletion. From the sixteen (16) Pf cox3 positive samples, five (5) samples were amplified giving the expected band sizes of $800 \mathrm{bp}$ and $900 \mathrm{bp}$ in accordance with (Koita et al., 2012) and eleven (11) samples were with no amplification. The eleven samples which showed negative PfHRP2 gene amplification indicated the possibility of having PfHRP2 gene deletion or cross reactivity between the PfHRP2 and PfHRP3 gene products. Therefore in the third stage, the eleven (11) samples were set for amplification of Pf HRP3. After the amplification of Pf HRP3-gene, ten (10) samples appeared positive with expected band sizes of $800 \mathrm{bp}, 400 \mathrm{bp}$ and $300 \mathrm{bp}$ in accordance with (Parr et al., 2018) and only one (1) sample was negative. This indicated a possibility for cross reactivity of Pf HRP2 for/with Pf HRP 3 which was found to be positive and/ or negative on the Pf HRP 2 RDT strip. According to (Parr et al., 2017), PfHRP3 antigen triggers a positive PfHRP2- based RDT because some Pf HRP2 antigens shares similar epitopes to Pf 
HRP3 antigens resulting to Pf HRP2-deleted parasites with an intact Pf HRP3 gene.

The final confirmatory PCR was carried out on the one (1) PfHRP3 negative sample for the amplification of Pf Beta tubulin in which no amplification was recorded, this could be as result of low limit of detection (LOD) or even absence of the amplicon (Parr et al., 2018).

The failure of a parasite to express its antigen on the PfHRP2-based RDT could be as a result of some possible factors; either due to genetic deletions as in deletion of PfHRP2 and PfHRP3 genes (Gamboa et al., 2010), frame shift mutations or alterations in protein expression (Wellems and Howard, 1986), storage and transport conditions of RDT, variability within the parasite antigen technique used to perform test, interpretation of test results or parasite density (Baker et al., 2010; Baker et al., 2005; Maltha et al., 2012).

This study found the existence of $P$. falciparum isolates lacking the HRP2 gene in the samples analyzed. Detection of Pf HRP3 gene in some of the samples, which appeared positive RDT, and negative Pf HRP2 gene confirmed the possibility of cross reactivity of Pf HRP2 and Pf HRP3 gene products on RDT. Also false-negative PfHRP2 RDTs with detection of Pf HRP3 gene in some of the samples has provided new information on the performance of Pf HRP2 RDTs in Nigeria which supports the previously raised concerns that the sensitivity of Pf HRP2 RDTs may decline as malaria control improves. More so, the current situation of Pf HRP2 RDTs has certainly compromised malaria diagnosis and treatment.

\section{Conclusions}

The existence of $P$. falciparum isolates lacking the HRP2 gene was confirmed in this study so also cross reactivity of Pf HRP2 and Pf HRP3 gene products. The study has confirmed the already raised fear of PfHRP2 gene deletion which will severely compromise malaria diagnosis and treatment. Based on this finding, there is a need to develop a unique RDT Kit targeting both PfHRP2 and PfHRP3 genes concomitantly in order to reduce the chances of having a false positive result. Furthermore, other house- keeping genes unique for Plasmodium falciparum can be considered for developing a kit with far greater sensitivity than the current ones.

\section{Acknowledgement}

The authors wish to acknowledge the Sokoto State Ministry of Health for the financial support throughout the study.

\section{Conflict of interest}

The authors declare no conflict of interest.

\section{References}

1. Adu-Gyasi D, Adams $\mathrm{M}$, Amoako $\mathrm{S}$, Mahama E, Nsoh M, Amenga-Etego S, Owusu-Agyei S et al. (2012) Estimating malaria parasite density: assumed white blood cell count of $10,000 / \mu$ l of blood is appropriate measure in Central Ghana. Malaria journal, 11(1), 1-6. https://doi.org/10.1186/1475-2875-11-238.

2. Baiden F, Webster J, Tivura M, Delimini R, Berko Y, Amenga-Etego S, Owusu-Agyei $S$ et al. (2012). Accuracy of rapid tests for malaria and treatment outcomes for malaria and non-malaria cases among under-five children in rural Ghana. PLoS One, 7(4), e34073.

https://doi.org/10.1371/journal.pone.00340 73.

3. Baker J, Ho M-F, Pelecanos A, Gatton M, Chen N, Abdullah S, Bell D et al. (2010) Global sequence variation in the histidinerich proteins 2 and 3 of Plasmodium 
falciparum: implications for the performance of malaria rapid diagnostic tests. Malaria journal, 9(1), 1-12. https://doi.org/10.1186/1475-2875-9-129.

4. Baker J, McCarthy J, Gatton M, Kyle DE, Belizario V, Luchavez J, Cheng Q (2005) Genetic diversity of Plasmodium falciparum histidine-rich protein 2 (PfHRP2) and its effect on the performance of PfHRP2-based rapid diagnostic tests. The Journal of infectious diseases, 192(5), 870-877. https://doi.org/10.1086/432010.

5. Cunningham J, Jones S, Gatton ML, Barnwell JW, Cheng Q, Chiodini PL, Luchavez J et al. (2019) A review of the WHO malaria rapid diagnostic test product testing programme (2008-2018): performance, procurement and policy. Malaria journal, 18(1), 1-15. https://doi.org/10.1186/s12936-019-3028-z.

6. Dorado EJ, Okoth SA, Montenegro LM, Diaz G, Barnwell JW, Udhayakumar V \& Murillo Solano C (2016) Genetic characterisation of Plasmodium falciparum isolates with deletion of the pfhrp2 and/or pfhrp3 genes in Colombia: the Amazon region, a challenge for malaria diagnosis and control. PLoS One, 11(9), e0163137. https://doi.org/10.1371/journal.pone.01631 37.

7. Draugalis JR, Plaza CM (2009) Best practices for survey research reports revisited: implications of target population, probability sampling, and response rate. American Journal of Pharmaceutical Education, 73 (8), 142. DOI: https://doi.org/10.5688/aj7308142

8. Echeverry DF, Deason NA, Davidson J, Makuru V, Xiao H, Niedbalski J, Collins FH et al. (2016) Human malaria diagnosis using a single-step direct-PCR based on the Plasmodium cytochrome oxidase III gene. Malaria journal, 15(1), 1-12. https://doi.org/10.1186/s12936-016-1185-x.

9. Fontecha G, Mejía RE, Banegas E, Ade MP, Mendoza L, Ortiz B, Pinto A et al. (2018) Deletions of pfhrp2 and pfhrp3 genes of Plasmodium falciparum from Honduras, Guatemala and Nicaragua. Malaria journal, 17(1), 1-10. https://doi.org/10.1186/s12936-018-2470-7. 10. Gamboa D, Ho M-F, Bendezu J, Torres K, Chiodini PL, Barnwell JW, McCarthy J et al. (2010) A large proportion of $\mathrm{P}$. falciparum isolates in the Amazon region of Peru lack pfhrp2 and pfhrp3: implications for malaria rapid diagnostic tests. PLoS One, 5(1), e8091. https://doi.org/10.1371/journal.pone.00080 91.

11. Gerstl S, Dunkley S, Mukhtar A, De Smet M, Baker S, Maikere J (2010) Assessment of two malaria rapid diagnostic tests in children under five years of age, with follow-up of false-positive $\mathrm{pLDH}$ test results, in a hyperendemic falciparum malaria area, Sierra Leone. Malaria journal, 9(1), 1-10.

https://doi.org/10.1186/1475-2875-9-28.

12. Gillet $P$, Scheirlinck A, Stokx $J$ et al. (2011) Prozone in malaria rapid diagnostics tests: how many cases are missed? Malaria journal, 10, 166. https://doi.org/10.1186/1475-2875-10-166

13. Iqbal J, Siddique A, Jameel M, Hira PR (2004) Persistent histidine-rich protein 2, parasite lactate dehydrogenase, and panmalarial antigen reactivity after clearance of Plasmodium falciparum monoinfection. Journal of clinical microbiology, 42(9), 4237-4241.

10.1128/JCM.42.9.4237-4241.2004.

14. Koita OA, Doumbo OK, Ouattara A, Tall LK, Konaré A, Diakité M, Doumbo SN et al. (2012) False-negative rapid diagnostic tests for malaria and deletion of the histidine-rich repeat region of the hrp2 
gene. The American journal of tropical medicine and hygiene, 86(2), 194-198. https://doi.org/10.4269/ajtmh.2012.100665.

15. Kumar A, Singh SP, Bhatt R, Singh V (2019) Genetic profiling of the Plasmodium falciparum parasite population in uncomplicated malaria from India. Malaria journal, 18(1), 1-11. https://doi.org/10.1186/s12936-019-3022-5.

16. Kumar N, Pande V, Bhatt R, Shah NK, Mishra N, Srivastava B, Anvikar AR et al. (2013) Genetic deletion of HRP2 and HRP3 in Indian Plasmodium falciparum population and false negative malaria rapid diagnostic test. Acta tropica, 125(1), 119121.

https://doi.org/10.1016/j.actatropica.2012.0 9.015 .

17. Lee N, Baker J, Andrews KT, Gatton ML, Bell D, Cheng Q, McCarthy J (2006) Effect of sequence variation in Plasmodium falciparum histidine-rich protein 2 on binding of specific monoclonal antibodies: implications for rapid diagnostic tests for malaria. Journal of clinical microbiology, 44(8), 2773-2778.

10.1128/JCM.02557-05.

18. Lee N, Gatton ML, Pelecanos A, Bubb M, Gonzalez I, Bell D, McCarthy JS et al. (2012) Identification of optimal epitopes for Plasmodium falciparum rapid diagnostic tests that target histidine-rich proteins 2 and 3 . Journal of clinical microbiology, 50(4), 1397-1405. 10.1128/JCM.06533-11.

19. Maltha J, Gamboa D, Bendezu J, Sanchez L, Cnops L, Gillet P, Jacobs J (2012) Rapid diagnostic tests for malaria diagnosis in the Peruvian Amazon: impact of pfhrp2 gene deletions and cross-reactions. PLoS One, 7(8), e43094. https://doi.org/10.1371/journal.pone.00430 94.
20. Maltha J, Gillet P, Bottieau E, Cnops L, van Esbroeck M, Jacobs J (2010) Evaluation of a rapid diagnostic test (CareStart $^{\mathrm{TM}} \quad$ Malaria HRP-2/pLDH (Pf/pan) Combo Test) for the diagnosis of malaria in a reference setting. Malaria journal, 9(1), 1-13. https://doi.org/10.1186/1475-2875-9-171.

21. Nakasi R, Mwebaze E, Zawedde A et al. (2020) A new approach for microscopic diagnosis of malaria parasites in thick blood smears using pre-trained deep learning models. SN Appl. Sci. 2, 1255. https://doi.org/10.1007/s42452-020-3000-0.

22. Parr JB, Anderson O, Juliano JJ, Meshnick SR (2018) Streamlined, PCR-based testing for pfhrp2-and pfhrp3-negative Plasmodium falciparum. Malaria journal, 17(1), 1-8. https://doi.org/10.1186/s12936018-2287-4.

23. Parr JB, Verity R, Doctor SM, Janko M, Carey-Ewend K, Turman BJ, Mwandagalirwa K et al. (2017) Pfhrp2deleted Plasmodium falciparum parasites in the Democratic Republic of the Congo: a national cross-sectional survey. The Journal of infectious diseases, 216(1), 36-44. https://doi.org/10.1093/infdis/jiw538.

24. Shakely D, Elfving K, Aydin-Schmidt B, Msellem MI, Morris U, Omar R, Baltzell KA et al. (2013) The usefulness of rapid diagnostic tests in the new context of low malaria transmission in Zanzibar. PLoS One, 8(9), e72912.

https://doi.org/10.1371/journal.pone.00729 12.

25. Skeet J (2005) Malaria: its causes, treatment and methods of prevention. Nursing times, 101(20), 43-45. PMID: 15918463 .

26. Wellems TE, Howard RJ (1986) Homologous genes encode two distinct histidine-rich proteins in a cloned isolate of Plasmodium falciparum. Proceedings of the 
National Academy of Sciences, 83(16), 6065-6069.

https://doi.org/10.1073/pnas.83.16.6065.

27. Wongsrichanalai C, Barcus MJ, Muth S, Sutamihardja A, Wernsdorfer WH (2007) A review of malaria diagnostic tools: microscopy and rapid diagnostic test (RDT). The American journal of tropical medicine and hygiene, 77(6_Suppl), 119127. PMID: 18165483.

28. Wurtz N, Fall B, Bui K, Pascual A, Fall M, Camara C, Diémé Y et al. (2013) Pfhrp2 and pfhrp3 polymorphisms in Plasmodium falciparum isolates from Dakar, Senegal: impact on rapid malaria diagnostic tests. Malaria journal, 12(1), 1-8.

https://doi.org/10.1186/1475-2875-12-34.

29. Zimmerman PA, Howes RE (2015) Malaria diagnosis for malaria elimination. Current opinion in infectious diseases, 28(5), 446454. 10.1097/QCO.0000000000000191. 